\title{
O estudo da forma urbana em Santa Catarina, Brasil
}

\author{
The study of urban form in Santa Catarina, Brazil
}

Renato Tibiriçá de Saboya[a] (1)

[a] Universidade Federal de Santa Catarina (UFSC), Programa de Pós-graduação em Arquitetura e Urbanismo, Florianópolis, SC, Brasil

Como citar: Saboya, R. T. (2020). 0 estudo da forma urbana em Santa Catarina, Brasil. urbe. Revista Brasileira de Gestão Urbana, 12, e20190269. https://doi.org/10.1590/2175-3369.012.e20190269

\section{Resumo}

Este artigo faz um apanhado geral da produção acadêmica acerca da forma urbana no Estado de Santa Catarina, Brasil. Para isso, classifica os estudos em três grandes categorias que servem como fio condutor das discussões e resgates: 1) história e evolução urbana; 2) perspectiva crítica; e 3) arquitetura da cidade. Dentro desta última, três subcategorias são definidas: a) a forma urbana do turismo e dos balneários; b) a vitalidade urbana e os tipos edilícios; e c) os tipos edilícios e a ocorrência de crimes. De forma geral, nota-se uma ausência de referências a autores importantes da morfologia urbana, tais como Conzen, Muratori e Cannigia, assim como uma predominância de trabalhos descritivos e discursivos sobre trabalhos conceituais ou quantitativos.

Palavras-chave: Forma urbana. Morfologia urbana. Evolução urbana. Arquitetura da cidade.

\section{Abstract}

This paper gives an overview of the academic studies related to the urban form in Santa Catarina, Brazil. In order to do this, these works were classified into three broad categories that serve as a framework for the discussion: 1) history and urban evolution; 2) critical perspective; and 3) city architecture. Within the last category, three subcategories were defined: a) the urban form of tourism and beach neighborhoods; b) urban vitality and building types; and c) building types and the occurrence of crimes. Overall, it was noted a lack of references to the works of important urban morphologists such as MRG Conzen, Muratori and Cannigia, as well as a prevalence of descriptive and discursive studies over more conceptual or quantitative ones.

Keywords: Urban form. Urban morphology. Urban evolution. City architecture. 


\section{Introdução}

Santa Catarina tem uma longa tradição de estudos sobre a forma urbana e sua evolução, os padrões recorrentes e as relações com aspectos socioeconômicos que lhe deram origem e com aqueles que sofrem seus efeitos. Este artigo busca fazer uma revisão de alguns principais dos trabalhos e das linhas de pesquisa relacionados a esses temas, sem, entretanto, a pretensão de esgotar o assunto ou apontar com algum nível de rigor quais seriam os trabalhos mais importantes e influentes. Em vez disso, propõe-se uma classificação geral em três grandes categorias, que organizam a estrutura do artigo e servem de fio condutor para o resgate de alguns estudos considerados relevantes para o quadro geral que se pretende caracterizar. Como ficará evidente, as fronteiras entre essas grandes categorias não são perfeitamente claras, com diversos trabalhos que atravessam de uma para outra e buscam realizar conexões. Considera-se, entretanto, que essa categorização geral ajuda enquanto aproximação a um contexto de produção intelectual rica e diversificada e, por isso, complexa. As categorias gerais são: 1) história e evolução urbana; 2) perspectiva crítica; e 3) arquitetura da cidade. Dentro desta última, propõem-se três subcategorias: a forma urbana do turismo e dos balneários; a vitalidade urbana e os tipos edilícios; e os tipos edilícios e a ocorrência de crimes.

Como critérios de seleção, os trabalhos incluídos neste artigo foram elaborados por pesquisadores de instituições de ensino catarinenses, e todos eles adotam como objeto de estudo áreas urbanas localizadas no Estado, apesar de haver muitos casos em que esses mesmos pesquisadores conduziram investigações em outros locais. Além disso, deu-se preferência a publicações em periódicos científicos e livros, em oposição a trabalhos em eventos, que tornariam o mapeamento e a revisão dos trabalhos um processo excessivamente complicado e longo.

\section{História e evolução urbana}

Um importante e pioneiro trabalho sobre a evolução urbana em Santa Catarina é o livro "Florianópolis: memória urbana", Veiga (2010), cuja primeira edição foi publicada em 1993. Ainda que não seja especificamente um trabalho de morfologia urbana, trata de diversos aspectos da forma urbana, sob uma abordagem mais descritiva e documental (ou "histórico-urbanística", em suas palavras), do que propriamente preocupada em conectar a forma a processos socioespaciais mais profundos. Por meio de vasta pesquisa bibliográfica, cartográfica, hemerográfica, normativa e iconográfica, entre outras fontes, 0 livro percorre toda a história da ocupação urbana do núcleo central de Florianópolis, desde sua fundação como Desterro até a década de 1930. Importante material cartográfico foi produzido pela pesquisadora na forma de mapas urbanos em diferentes períodos, cartograficamente mais precisos do que os originais disponíveis, que eram de difícil leitura e interpretação. Esses mapas incluem os limites da cidade, o arruamento, os principais equipamentos urbanos (igrejas, hospitais, fontes, chafarizes, pelouro etc.) e caminhos semirrurais, e têm sido amplamente utilizados como referência por outros trabalhos. Por meio deles, é possível perceber a alta permanência do traçado, especialmente quando se compara a outros elementos do sistema urbano, como edificações e usos do solo específicos. As praças, por sua vez, possuem grau de permanência intermediário, com grande parte delas ainda existentes atualmente. 

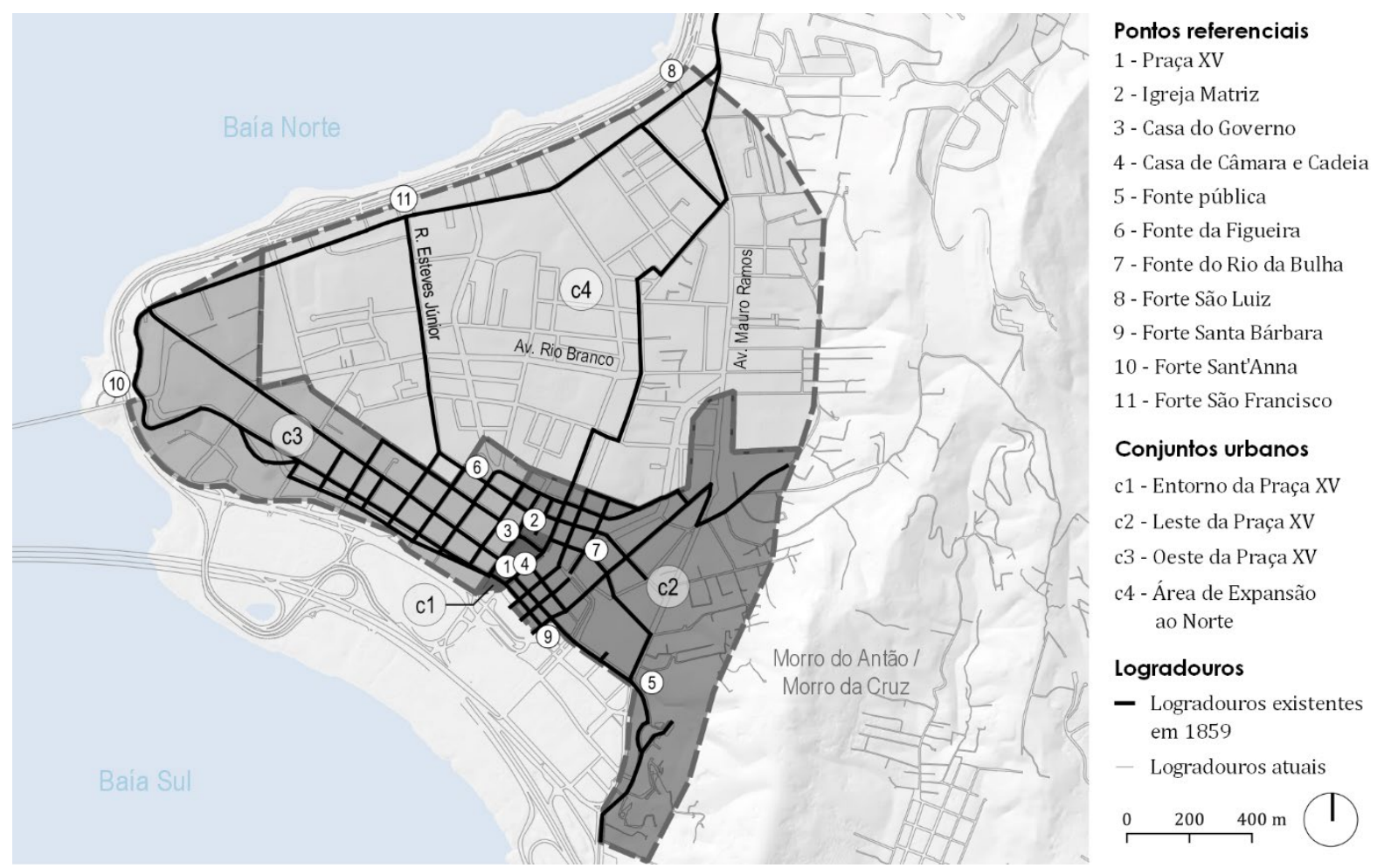

Figura 1 - Mapa aproximado dos conjuntos urbanos definidos por Veiga (2010), com as vias existentes em 1819 e os referenciais históricos importantes. Fonte: Elaborada pelo autor a partir de mapa de Veiga (2010) sobre dados da Prefeitura Municipal de Florianópolis.

Para caracterizar o processo de consolidação e expansão do núcleo fundador, Veiga (2010, p. 165) define quatro conjuntos urbanos que, segundo ela, possuem construções que, “[...] geralmente agrupadas em alguns quarteirões, têm quase sempre uma ligação característica, seja na volumetria, no estilo ou na linguagem arquitetônica" (Figura 1): 1) o conjunto imediatamente ao redor da Praça XV, origem da cidade; 2) os aglomerados iniciais a leste da praça; 3) as concentrações e os eixos de expansão a oeste; e 4) os eixos de expansão mais recente, em direção ao norte. Apesar de claramente relacionados ao conceito de regiões morfológicas de Conzen (2004), não são explicitamente mencionados.

Para o conjunto da Praça XV, Veiga (2010) concentra-se na descrição da substituição tipológica que transformou, progressivamente, o conjunto de pequenas casas térreas em sobrados destinados às camadas de renda mais alta. A leste da praça, as construções eram mais simples e pobres e se alinhavam de maneira orgânica em um traçado mais sinuoso, adaptando-se mais livremente à topografia e aos cursos d'água, contrastando com a grelha rígida e regular que marcou o entorno da praça e a região a oeste. Esta concentrou os eixos de desenvolvimento por causa da presença de importantes equipamentos como o Porto de Desterro, a Alfândega e o Mercado Público e, mais tarde, por ser ligação com a Ponte Hercílio Luz, única conexão viária da Ilha com o continente na época. Assim, Veiga (2010) sinaliza a influência tanto da localização de grandes polos atratores quanto da acessibilidade proporcionada pela malha viária na intensidade da dinâmica urbana e na distribuição das classes sociais no espaço, tema retomado mais tarde por Sugai (2015) para outro período histórico.

Nessas três regiões, a substituição tipológica caminhou na direção de edificações residenciais de um pavimento para edificações mistas de dois pavimentos, com comércio no térreo e residência em cima, construídas nos alinhamentos frontais e sem afastamentos laterais entre si, conformando um conjunto relativamente homogêneo, compacto e contínuo, aspectos abordados em trabalhos recentes (Saboya et al., 2015; Netto et al., 2019).

O quarto conjunto descrito por Veiga (2010) englobava as terras ao norte da Praça XV, até então ocupadas por chácaras, em direção à Praia de Fora, atual Beiramar Norte. 0 primeiro eixo foi a Rua Esteves Júnior, que conectava o Centro aos Fortes São Francisco e São Luiz e que faziam parte das defesas 
da Ilha de Santa Catarina. Outros eixos importantes foram a Avenida Mauro Ramos, que seguia o sopé do Morro do Antão (atual Morro da Cruz) e dava acesso às olarias, e a Avenida Rio Branco, mais recente e que consolidou a transformação da região das chácaras em área urbana. A tipologia edilícia nessa região desenvolveu-se de maneira ligeiramente diferente das demais, com o surgimento e a consolidação da residência térrea com porão, que elevava o pavimento térreo em relação à altura do passeio e, mais tarde, seria amplamente utilizada nos outros conjuntos urbanos de Florianópolis (Veiga, 2010).

Esse crescimento, por meio de caminhos que orientam a transformação de parcelas rurais em lotes urbanizados, é, de certa forma, estendido para o restante da Ilha e analisado em profundida no trabalho de Reis (2012). 0 autor elenca quatro componentes fundamentais desse processo: a) a rede de núcleos pesqueiros e agrícolas, que se espalhou pelo território da Ilha de Santa Catarina; b) os caminhos gerais, aquáticos e terrestres, que ligavam essas localidades entre si e com o centro principal; c) as propriedades rurais parceladas; e d) as áreas comunais, grandes extensões de terra destinadas a pastagens coletivas e sem proprietários específicos.

Os núcleos tradicionais se formaram em meados do século XVIII, em grande parte em decorrência da imigração açoriana fomentada pela Coroa Portuguesa. Praticamente todos se instalaram junto ao mar, refletindo as condições de transporte da época. Os caminhos foram aos poucos sendo construídos posteriormente para interligar esses núcleos e, em regra, evitavam os mangues, as dunas e as declividades acentuadas, mantendo-se ao sopé dos morros, o que lhe conferia formas serpenteantes que se originavam no núcleo principal e seguiam paralelas ao mar, ao sul e ao norte, e se interiorizavam em algumas porções do território. Segundo Reis (2012), sua função principal, além de interligar os núcleos, era dar acesso às propriedades rurais que, compridas e estreitas, posicionavam-se com seu menor lado voltado para os caminhos. Essa estrutura morfológica foi determinante para a evolução urbana e crescimento da cidade de Florianópolis: à medida que as famílias cresciam ou havia demanda por lotes urbanizados, essas parcelas eram desmembradas em partes menores, sempre paralelamente à via principal, e sem um plano que conferisse alguma noção de conjunto ao resultado da justaposição de diferentes parcelamentos (Reis, 2012). Pequenas vias eram abertas apenas com o intuito de conferir acesso aos lotes, que, como resultado da divisão da gleba original, perdiam ligação direta ao caminho principal. Por isso, esses caminhos acabavam extremamente estreitos, não raro permitindo a passagem de apenas um veículo por vez e sem conexão com outras vias a não ser a via principal. Isso, por sua vez, acabou criando situações em que esses caminhos acabaram sobrecarregados por uma dupla função: estruturar as localidades das quais faziam parte e concentrar os fluxos de passagem (Reis, 2012).

Além desses padrões típicos, outros padrões também são recorrentes na forma urbana da Ilha de Santa Catarina, ainda que não sejam tão frequentes: densificação, substituição tipológica e mudanças no uso do solo dos núcleos urbanos antigos; implantação de grandes equipamentos voltados tanto à atividade turística quanto a outras funções e desconectados do tecido urbano, tais como resorts, centros de compras e centros tecnológicos; e favelas, que costumam se localizar em áreas com limitações ambientais, riscos à ocupação e indefinição sobre a propriedade (Reis, 2012).

\section{A tradição sintática}

Santa Catarina tem uma tradição em estudos sintáticos que remonta à década de 1990, quando os professores Almir Francisco Reis e Ayrton Portilho Bueno realizaram seus mestrados em Brasília sob orientação de Frederico de Holanda, trazendo a teoria da sintaxe espacial para a Universidade Federal de Santa Catarina, que, à época, ainda não contava com a pós-graduação em Arquitetura e Urbanismo. Os estudos que deram continuidade aos trabalhos de mestrado foram, então, desenvolvidos na graduação, especialmente no Grupo Pet, mas também nas disciplinas de Projeto Arquitetônico e Desenho Urbano, ainda que, no caso das disciplinas, fossem utilizados mais os fundamentos dessa teoria do que propriamente suas técnicas analíticas matematizadas. 


\section{Estudos pioneiros}

Reis \& Holanda (2017, p. 20), em trabalho derivado de dissertação do primeiro defendida em 1993, fizeram uma análise sintática do Centro de Florianópolis, buscando investigar "[...] como sua configuração física se relaciona com a efetiva apropriação de seus lugares abertos de uso coletivo". Duas técnicas de análise foram utilizadas, cada uma permitindo a descrição do espaço em categorias: (1) a axialidade permitiu analisar a integração, medida clássica da sintaxe espacial relacionada ao inverso da profundidade média de uma linha axial ao restante do sistema; (2) a regularidade da trama; e (3) a inteligibilidade, medida, neste caso, pela correlação entre o valor de integração de uma linha axial e sua conectividade. A segunda técnica, convexidade, permitiu a análise das categorias: (1) proporção de áreas abertas de uso coletivo em relação à área total; (2) delimitação dos espaços convexos; (3) tamanho dos espaços convexos; e (4) constitutividade dos espaços convexos, ou seja, o número de portas que se abrem para eles.

O estudo é claramente limitado pelos recursos tecnológicos da época, quando computadores, sistemas de informações geográficas e softwares para o cálculo de medidas sintáticas não estavam tão desenvolvidos e amigáveis aos usuários como atualmente. Assim, grande parte do trabalho teve de ser feita à mão, o que acabou limitando a área modelada pelas linhas axiais à região central de Florianópolis, mas não prejudicou a validade e a relevância das análises.

Reis \& Holanda (2017, p. 27) ressaltaram as diferenças morfológicas entre o núcleo fundador, sua expansão imediata e as expansões posteriores, mais recentes, representadas pelos aterros. Enquanto os dois primeiros são chamados de "paisagem de lugares" e caracterizados por vazios "escavados na densa massa edificada" com muitas portas se abrindo para eles, a última é uma "paisagem de objetos", com edifícios espalhados em grandes áreas vazias e com grande quantidade de empenas cegas. Essas características mostraram-se, além disso, intimamente associadas ao uso do solo e à apropriação pelos pedestres, o que foi mais intensa justamente no núcleo mais antigo, que também contava com os maiores valores de integração.

Ângelo et al. (2017), em estudo de 1996 orientado por Ayrton Bueno, investigaram a medida sintática de integração e sua relação com os elementos da imagem da cidade definidos por Lynch (1960) com o uso de mapas mentais, metodologia "[...] sistematizada e adaptada para o caso brasileiro por Kohlsdorf (1996)" (Ângelo et al., 2017, p. 79). O estudo envolveu a construção de mapa axial e aplicação de questionários com perguntas abertas a moradores do bairro do Campeche, localizado na porção sudeste da Ilha de Santa Catarina. 0 mapa de integração revelou que o núcleo integrador, composto de $10 \%$ das linhas mais integradas, concentrava-se em algumas poucas linhas principais que cobriam pouco da área total do bairro, indicando certa segregação em relação ao resto da cidade e maior dificuldade para a apropriação e a circulação de pessoas estranhas ao bairro.

Mais interessante, entretanto, foi a constatação de que os caminhos revelados pelos questionários como aqueles mais importantes para a imagem mental que os moradores possuíam do bairro coincidiam com as linhas mais integradas apontadas pela análise sintática, revelando uma conexão importante entre as imposições da forma física em termos de barreiras e permeabilidades, por um lado, e aspectos mais subjetivos da percepção dos moradores sobre seu próprio bairro, por outro. Isso foi reforçado pela constatação de que os marcos referenciais e os pontos focais também se localizavam junto às linhas mais integradas do sistema. A relação entre características sintáticas e limites foi menos pronunciada, mas os autores conseguiram perceber que estes estavam associados às rupturas no tecido, que impunham descontinuidades na movimentação pelo bairro e, por isso, refletiam-se em imagens também descontínuas para os moradores. 


\section{Estudos recentes}

Uma nova leva de estudos sintáticos, mais recentes e orientados por uma abordagem quantitativa, começou a acontecer depois de 2010. Carvalho \& Saboya (2017) estudaram a verticalização em Florianópolis usando as medidas de integração e escolha em análises axiais. A abordagem buscou conectar aspectos da economia urbana, mais especificamente a busca pela maximização do lucro, com uma descrição mais detalhada das localizações urbanas. 0 referencial teórico, com base em autores como Krafta (1994), Villaça (2001) e Abramo (2001), argumentou que as medidas sintáticas poderiam auxiliar a iluminar o dilema enfrentado por empreendedores no momento de escolher a localização das edificações verticais. Esse processo envolve uma negociação entre a opção por terras mais baratas, que maximizariam o lucro, ou por terras mais bem localizadas, que permitiriam maior preço final de venda. 0 método envolveu a comparação entre as medidas sintáticas para as vias em que a verticalização aconteceu e para a cidade como um todo. Foram feitas também diferenciações entre a área central e os balneários, décadas de construção e número de pavimentos. As principais conclusões apontam que:

Ao longo das décadas, as localizações buscaram, inicialmente, áreas mais integradas e com maior Escolha, até um determinado momento em que essas medidas atingiam um valor máximo; depois disso, iniciaram um processo de queda e posterior "interiorização" dos ERVs [Edificações Residenciais Verticais], caracterizada pela busca por vias com menor escolha, mais distantes das principais vias estruturadoras da localidade. (Carvalho \& Saboya, 2017, p. 428).

A diferença na capacidade explicativa das duas medidas sintáticas também foi uma conclusão importante. A integração, que é uma medida de proximidade e, por isso, varia gradativamente no espaço, sem grandes saltos, mostrou-se adequada a identificar áreas gerais da cidade que possuem maior potencial de verticalização. Entretanto, dentro de cada área, apenas a escolha, que é uma medida do quanto uma via tende a ser usada como passagem, foi capaz de diferenciar ruas próximas umas às outras e contribuir para explicar a presença de edificações verticais.

Saboya et al. (2016b) realizaram o primeiro estudo utilizando as novas técnicas sintáticas de representação do espaço por meio de segmentos, com distâncias entre eles capturadas a partir de distâncias angulares (Turner, 2007), e não mais por linhas axiais e distâncias topológicas. Os autores notaram a intensa descontinuidade do traçado, especialmente na porção insular, causada tanto por aspectos ambientais (lagoas, morros, mangues e dunas) quanto pelos processos históricos de parcelamento das propriedades rurais, conforme abordado na seção anterior. A rede de caminhos se estrutura em anéis apenas na parte mais consolidada do continente; no restante e, especialmente na Ilha, apresenta uma configuração em árvore, com vias principais organizadas em estruturas lineares que geram interstícios que não se conectam entre si, dificultando o acesso entre eles e concentrando os fluxos em relativamente poucas linhas. Isso, por sua vez, dificulta o surgimento de centralidades locais fortes, ajudando a perpetuar a dependência dos bairros à centralidade principal.

Kronenberger \& Saboya (2019) realizaram um estudo detalhado dos padrões de segregação configuracional na Área Conurbada de Florianópolis, que abrange, além da capital, os municípios de São José, Palhoça e Biguaçu. Mais uma vez, a aposta foi a de que a caracterização da localização intraurbana oferecida pelas medidas sintáticas seria capaz de proporcionar uma visão mais precisa do fenômeno da segregação, em oposição a descrições puramente verbais - e muitas vezes ambíguas -, como "regiões gerais", "centro" ou "anéis periféricos". A descrição dos aspectos socioeconômicos também recebeu especial atenção, indo além das medidas de renda tradicionalmente adotadas para estudar segregação. Por meio de um modelo AHP (Analytic Hierarchy Process) (Saaty, 1990), os autores criaram um índice socioeconômico composto de cinco dimensões: renda, educação (porcentagem de pessoas alfabetizadas), habitação (banheiros por morador), infraestrutura (banheiros exclusivos, coleta de lixo e disponibilidade de energia elétrica) e vizinhança (iluminação pública, pavimentação, presença de esgoto a céu aberto e lixo acumulado). As informações foram todas coletadas do Censo do IBGE (2010), em esfera do setor censitário, para permitir sua reprodução em outros municípios brasileiros. A Figura 2 mostra a espacialização do índice socioeconômico, que vai de 0,0 (situação de maior precariedade) a 1,00 (melhores condições socioeconômicas), e os mapas de integração e escolha global. 

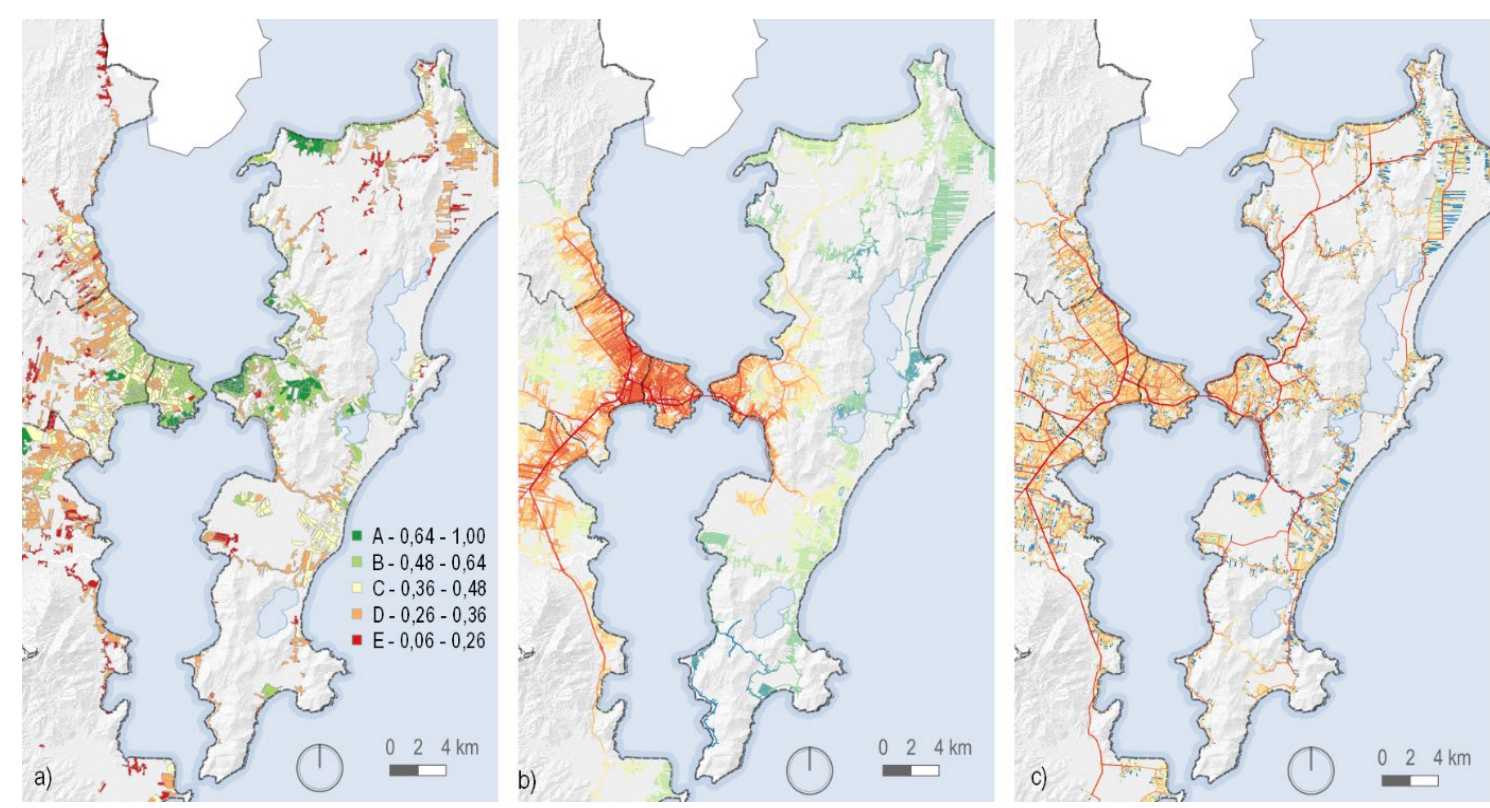

Figura 2 - (a) Índice socioeconômico; (b) integração global (raio n) para segmentos e distância angular; e (c) escolha global (raio n) para segmentos e distância angular. Fonte: Kronenberger \& Saboya (2019).

Os padrões encontrados em escala global foram: a) classes privilegiadas localizadas em vias de alta acessibilidade (integração e escolha), mas não as mais altas, possivelmente para evitar os incômodos normalmente associados às vias de maior movimentação de pessoas e veículos; b) concentração de atividades não residenciais e empregos em setores com valores intermediários do índice socioeconômico; e c) proximidade de setores com menor índice socioeconômico às vias de passagem na escala global, mas apenas quando estas possuem características de via expressa, e não quando possuem amenidades ambientais ou estão em áreas centrais. Já na escala local, os autores encontraram que a descontinuidade do traçado é frequentemente utilizada como estratégia para separar setores com índices socioeconômicos contrastantes (Kronenberger \& Saboya, 2019).

\section{A perspectiva crítica: forma urbana, segregação e poder}

Sugai (2015) examinou os efeitos dos investimentos públicos na forma da cidade e nos padrões de segregação socioespacial de Florianópolis e municípios vizinhos conurbados. A partir de uma perspectiva crítica, com base em Lefebvre (2008), Lojkine (1997), Villaça $(2001,2012)$, entre outros autores de matriz marxista, parte-se da premissa de que a segregação espacial não é apenas um produto da desigualdade espacial, mas também uma estratégia essencial para a reprodução da dominação exercida pela classe que detém o poder. A partir disso, investiga mais especificamente os investimentos públicos realizados entre 1970 e 2000 e seus efeitos no aumento da segregação na Área Conurbada de Florianópolis, bem como a atuação e os interesses dos agentes atuantes nesse processo.

Para os propósitos deste apanhado histórico, o caso mais emblemático estudado por Sugai (2015) é, provavelmente, o da constituição de um "eixo rodoviário privilegiado", que conectava o acesso à Ilha aos balneários ao norte, para onde as áreas residenciais das classes dominantes estavam se expandindo (Figura 3). 0 "Plano de Desenvolvimento Integrado", elaborado entre 1969 e 1971 e aprovado como Plano Diretor em 1976, previa, entre outras diretrizes, a urbanização e o adensamento da planície do Campeche, situada na porção sudeste da Ilha de Santa Catarina e chamada de "Setor Oceânico Turístico". Essa intenção seria alcançada por meio da criação e ampliação de uma rede de vias estruturadoras que facilitariam o acesso, a partir do núcleo fundador de Florianópolis, à porção sudeste da Ilha, incluindo vias expressas e rodovias. Apesar de haver previsão de vias por toda a Ilha, essa conexão ao Setor Oceânico Turístico recebeu prioridade no plano. 


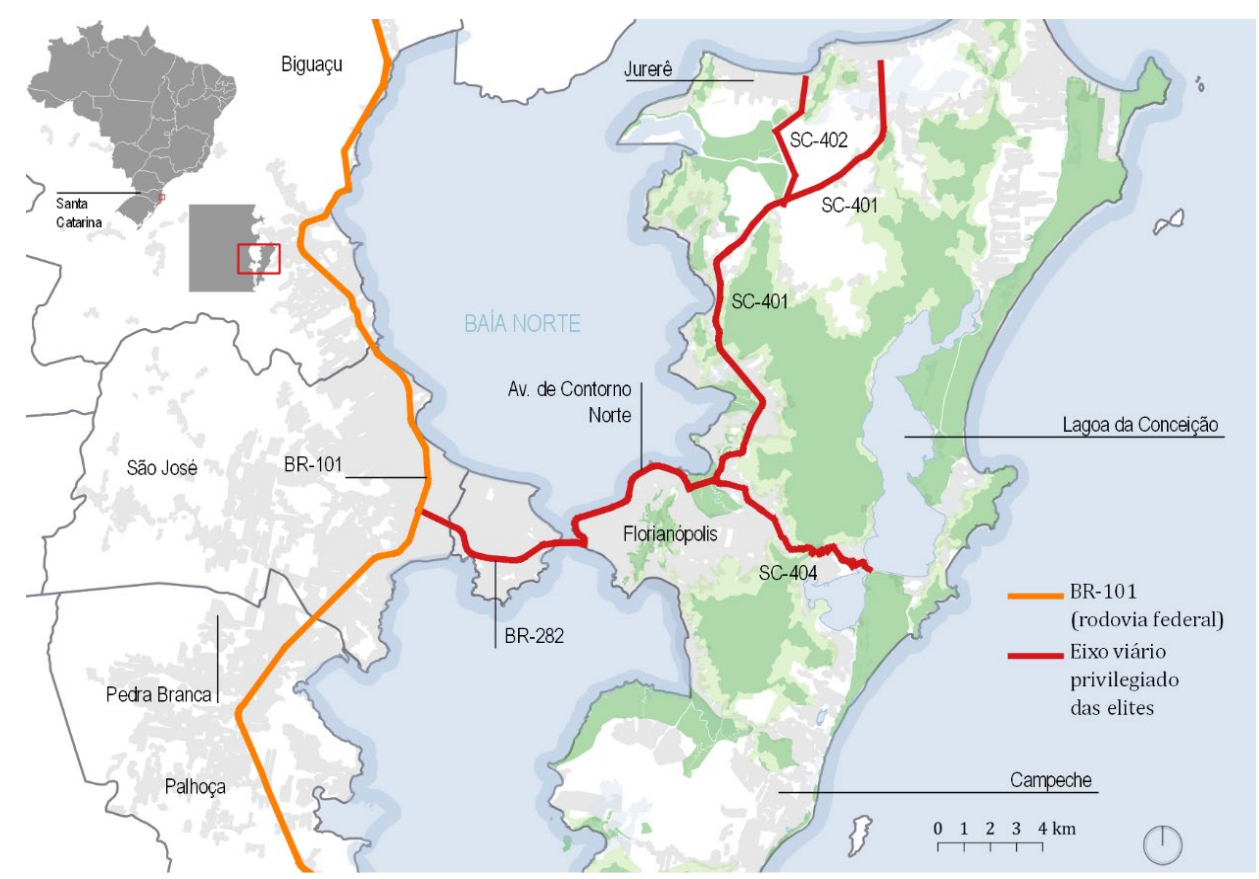

Figura 3 - "Eixo privilegiado das elites", identificado por Sugai (2015). Fonte: Adaptada de Kronenberger \& Saboya (2019).

Entretanto, esse direcionamento contrariava os interesses das elites, que vinham expandindo suas áreas residenciais na direção norte já há algumas décadas e onde já possuíam propriedades e interesses de adensamento e intensificação da urbanização. Como resultado, uma série de modificações foi realizada nos planos, o que permitiu direcionar os recursos públicos para a consolidação do eixo norte, tanto pela ampliação de novos eixos rodoviários quanto pela construção e implementação de diversos equipamentos públicos importantes ao longo desses eixos, tais como o Hospital Infantil Joana de Gusmão, a Celesc (concessionária de energia elétrica), a Udesc (universidade estadual) e o Centro Administrativo do Governo do Estado.

Essa combinação de acessibilidade viária e de concentração de equipamentos com alta capacidade de atrair pessoas gerou mudanças profundas na forma urbana e na estrutura de Florianópolis. Sugai (2015) relata que, na década de 1980, 64\% dos loteamentos aprovados localizavam-se próximo ao eixo privilegiado e nos balneários ao norte da Ilha. Com esse grande adensamento populacional, houve intensificação dos usos comerciais e construção de inúmeros empreendimentos privados, tais como escolas, centros tecnológicos, clubes, restaurantes etc. Como resultado, o valor do solo aumentou exponencialmente desde a década de 1970, e as camadas populares vêm sendo progressivamente expulsas para a periferia da área conurbada no continente.

O estudo de Sugai (2015) concilia uma perspectiva crítica com aspectos morfológicos - ainda que a ênfase não tenha sido nestes últimos - e mostra como a forma urbana é moldada por uma rede complexa de fatores, dos quais os investimentos públicos, capturados pelos interesses das classes dominantes, são parte importante. Estudos com esse perfil ainda são raros em Santa Catarina e representam uma linha de investigação que merece ser aprofundada, especialmente com a utilização de descrições mais apuradas e detalhadas da forma urbana. 0 trabalho de Kronenberger \& Saboya (2019), descrito anteriormente, avança nessa direção sob uma perspectiva configuracional; entretanto, outros aspectos morfológicos ainda são pouco explorados, tais como as características do parcelamento do solo, os sistemas de espaços livres e as tipologias arquitetônicas em áreas de pobreza e segregadas. Outro aspecto que merece maior atenção são os efeitos da forma urbana segregada sobre as condições de vida da população, uma vez que tanto o trabalho de Sugai (2015) quanto o de Kronenberger \& Saboya (2019) se concentraram mais nos processos que resultaram na forma do que nas consequências desta para a qualidade de vida urbana. 


\section{Arquitetura da cidade: padrões morfológicos urbano-arquitetônicos e seus efeitos}

A década de 2000 foi marcada pela criação de dois programas de pós-graduação vinculados ao Departamento de Arquitetura e Urbanismo. 0 primeiro deles, Programa de Pós-Graduação em Arquitetura e Urbanismo (PósARQ), foi criado em 2002, e o segundo, Programa de Pós-Graduação em Urbanismo, História e Arquitetura da Cidade (PGAU-Cidade), em 2005. Isso proporcionou novo impulso aos estudos morfológicos em Santa Catarina, atraindo estudantes de todo o Estado e de outras regiões do país - e mesmo de outros países. Além disso, a intensa renovação no quadro docente da UFSC, que começou em 2006 e continua acontecendo, tem trazido também novos pesquisadores e novas abordagens, que se somam àquelas já existentes e têm expandido as áreas de atuação e interesse das pesquisas sobre a forma urbana em Santa Catarina. Digna de nota também é a criação da Coleção "Urbanismo e Arquitetura da Cidade", que já publicou 13 livros sobre diferentes aspectos do urbanismo e da história da cidade, diversos deles voltados aos aspectos morfológicos. A coleção foi originalmente criada e conduzida pelo PGAU e, atualmente, é mantida pelo PósARQ, depois da fusão dos dois programas no final de 2014 e início de 2015.

\section{A forma urbana do turismo e dos balneários}

Por causa da centralidade de Florianópolis na produção de estudos relacionados à morfologia urbana em Santa Catarina, o turismo e os espaços resultantes dessa atividade receberam bastante atenção ao longo do tempo. Bueno \& Holanda (2017), em trabalho derivado da dissertação de mestrado do primeiro, concluída em 1996, estudaram três balneários da Ilha de Santa Catarina e suas estruturas sintática, funcional e de apropriação. Os núcleos originais dos balneários eram formados por capelas e algumas casas que se estendiam pelas encostas dos morros, explorados para agricultura e extrativismo. As planícies entre os morros e o mar, por outro lado, foram deixadas sem ocupação, constituindo-se em espaços coletivos para pastagens denominados "terras comunais". A partir da década de 1950, começaram a surgir na Ilha loteamentos destinados ao turismo e à segunda residência de moradores de Florianópolis ocupando essas terras comunais, sendo o primeiro em Canasvieiras, no norte da Ilha. Reis (2012) chama esses parcelamentos de "ordenados", em contraposição aos "parcelamentos simples" surgidos de maneira mais espontânea ao longo do tempo (Figura 4). As conclusões de Bueno \& Holanda (2017) apontam para uma relação conflituosa entre esses dois tipos de parcelamento nos balneários de Canasvieiras, Jurerê e Barra da Lagoa. Enquanto nos dois primeiros a estrutura sintática dos novos parcelamentos se integrava à configuração dos núcleos preexistentes, na Barra da Lagoa não houve integração entre as porções do tecido urbano. Além disso, no que diz respeito aos núcleos funcionais, nos três casos os novos parcelamentos procuraram segregar seus centros de comércios e serviços dos usos já consolidados, contribuindo para uma separação na apropriação e no contato entre moradores e turistas. 


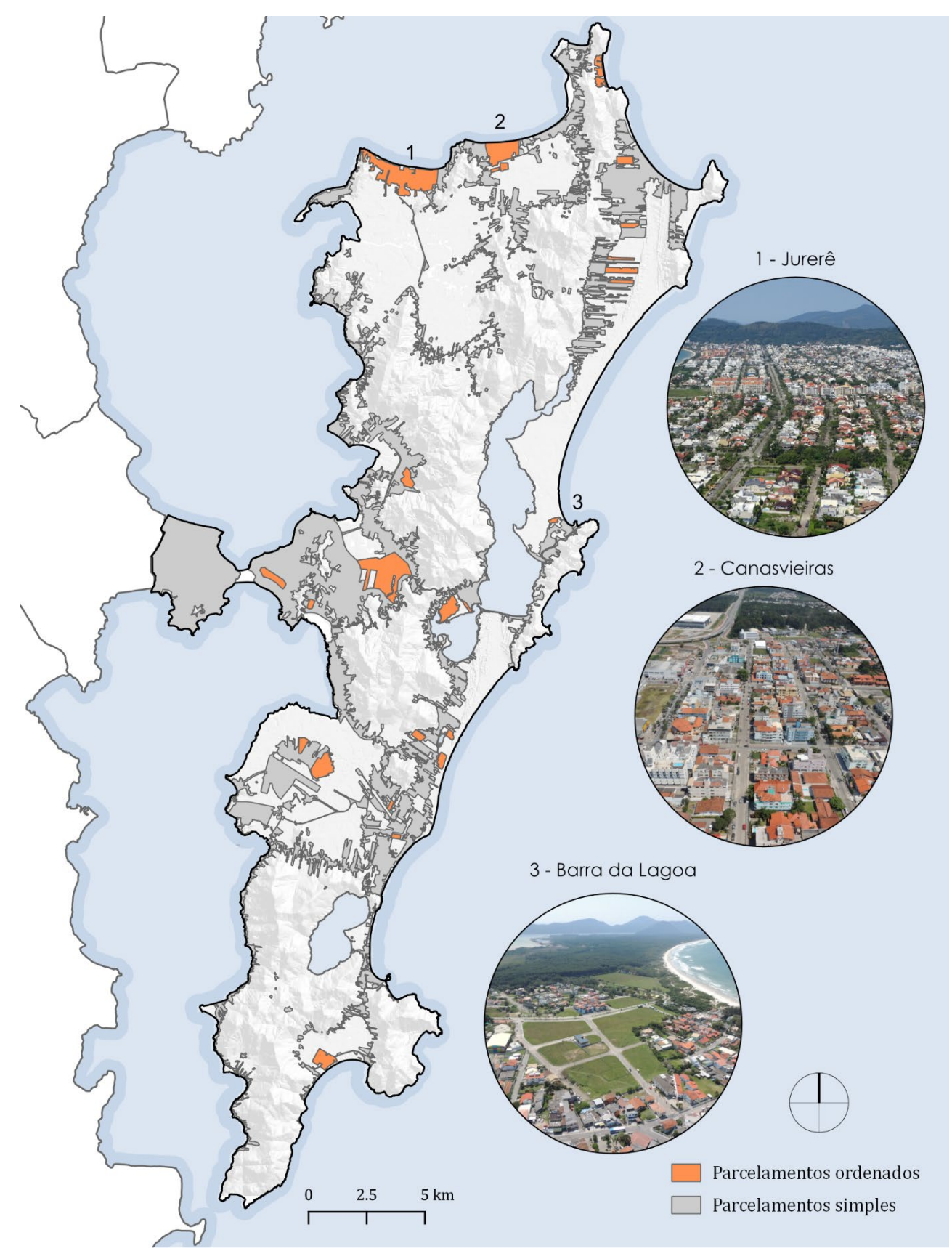

Figura 4 - Localização aproximada dos parcelamentos simples e ordenados em Florianópolis. Fonte: adaptada e atualizada pelo autor a partir de Reis (2012) e de dados da Prefeitura Municipal de Florianópolis. Fotos de 2016 por Sílvio Soares Macedo, doadas ao laboratório de Urbanismo da UFSC e disponibilizadas em Flickr (2019).

Saindo da Ilha de Santa Catarina, Skalee \& Reis (2008) descreveram o processo de urbanização de Balneário Camboriú e notaram que a maior parte do parcelamento do solo aconteceu no período que vai da Segunda Guerra Mundial à abertura da BR-101, que corta o município de norte a sul. Esse parcelamento aconteceu, principalmente, por meio de loteamentos juntos ao mar que não obedeciam a um plano geral. Como resultado, a quase totalidade das ruas foi desenhada no sentido perpendicular ao mar, otimizando o acesso a ele, mas restringindo bastante as conexões entre elas. 0 parcelamento rural preexistente condicionou fortemente esses projetos, estabelecendo três orientações ligeiramente diferentes para as vias que, não obstante, estão todas estruturadas em direção à praia. As poucas vias que realizam conexões importantes paralelas à orla são, atualmente, responsáveis pela estruturação do tecido urbano e concentram grande parte da apropriação e do movimento de pessoas. 0 adensamento por 
edificações aconteceu ainda na década de 1950 percorrendo a toda a orla, com pequenas edificações, explodindo a partir da década de 1970 com uma verticalização intensa.

Sadowski \& Rossetto (2018) analisaram a forma urbana do bairro dos Ingleses, localizado no norte da Ilha de Santa Catarina, relacionando-a aos aspectos naturais e sociais. Os autores reconheceram os mesmos processos de parcelamento tradicionais, descritos por Reis (2012), e notaram coincidência entre maior integração sintática global (nos limites do bairro, entretanto) e local e maior incidência de logradouros de menor escala. Em seguida, fizeram uma simulação do impacto da criação de um parque linear ao longo do Rio Capivari e, diante do aumento significativo na integração sintática, defenderam a necessidade e a potencialidade de uma maior integração entre os elementos naturais e a estrutura urbana para gerar espaços com maior urbanidade.

Outro núcleo de pesquisa importante sobre o turismo em Santa Catarina é constituído por docentes da Universidade do Vale do Itajaí, que possui um programa de pós-graduação com mestrado e doutorado em Turismo e Hotelaria. Os trabalhos desse núcleo possuem ênfases mais voltadas a aspectos econômicos e de gestão do que propriamente morfológicos, mas alguns deles navegam por temas relacionados a estes últimos. Em Tomelin et al. (2012), por exemplo, o foco foi a paisagem dos cascos históricos de Itajaí e São Francisco do Sul. Com base em autores como Lynch (1960), Cullen (1983) e Rossi (2001), foi feita uma leitura de ruas e conjuntos urbanos das duas cidades, identificando planos de composição, padrões como idade e altura das edificações e elementos referenciais importantes.

\section{Vitalidade urbana e tipos edilícios}

Mais recentemente, foi desenvolvida uma série de estudos envolvendo características mais detalhadas dos tipos arquitetônicos e sua relação com aspectos da vitalidade urbana. Esses estudos se caracterizavam por uma mudança no tipo de abordagem até então comumente utilizada para o estudo de padrões morfológicos, de natureza qualitativa, para estudos mais quantitativos, que buscavam selecionar amostras representativas de conjuntos maiores e obter resultados que pudessem ser generalizados para essas populações mais amplas. A maioria adotou técnicas estatísticas simples para a análise de dados, como a correlação, enquanto alguns mais recentes incorporaram outras ferramentas mais refinadas, por exemplo, análises de agrupamento (clustering) e regressões múltiplas.

Saboya et al. (2015) examinaram a relação entre movimento de pedestres e características edilícias em Florianópolis como parte de um estudo mais amplo que englobou também Rio de Janeiro (Netto et al., 2012) e Porto Alegre. Ao todo, foram 169 trechos de logradouros em 19 áreas da cidade, abrangendo 1.225 edificações. As edificações foram classificadas em três tipos básicos (Figura 5): o primeiro, compacto / contínuo, possuiria poucos afastamentos frontais e laterais, maior densidade de aberturas (portas e janelas) e interfaces mais abertas com o passeio; o segundo, isolado / torre, apresentaria as características inversas; o terceiro, híbrido, teria bases compactas e contínuas e torres isoladas. Este último tipo recebeu menor ênfase no estudo, por isso seus efeitos não puderam ser estimados. 


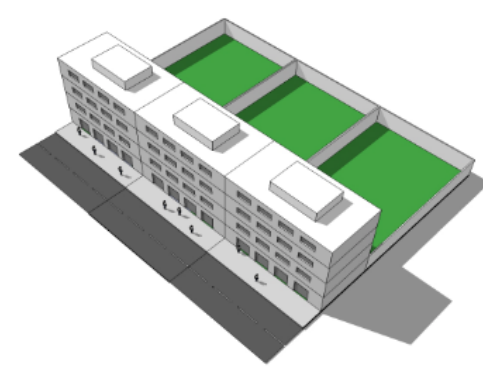

Tipo compacto / contínuo

- Sem afastamentos laterais e frontais;

- Sem grades ou muros;

- Maior relação visual com a rua;

- Maior número de portas voltadas para rua.

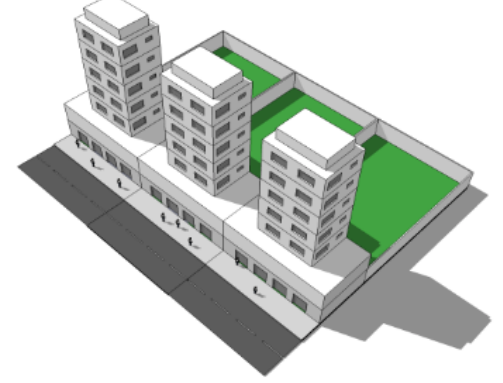

Tipo híbrido

- Base compacta e contínua;

- Torres isoladas.

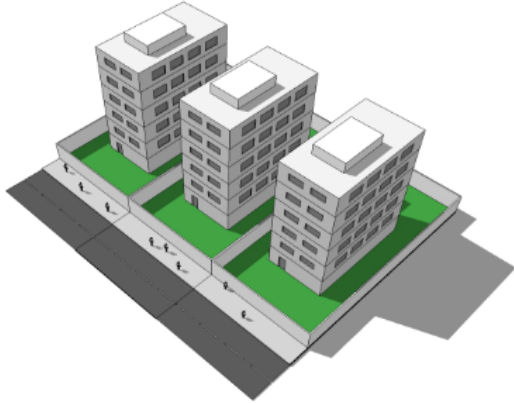

Tipo isolado / torre

- Afastamentos laterais e frontais;

- Grades ou muros;

- Menor relação visual com a rua;

- Menor número de portas voltadas para a rua.

Figura 5 - Tipos compacto/contínuo, híbrido e isolado/torre. Fonte: Adaptada de Saboya et al. (2015).

Essa caracterização foi testada estatisticamente mais tarde (Netto et al., 2019) por meio de um teste de associação entre as características morfológicas de cada tipo para averiguar se fazia realmente sentido agrupá-las nesses dois (ou três) tipos gerais. A Figura 6 mostra um dendrograma que agrupa características morfológicas de 4.038 edificações em Porto Alegre pelo quão "próximas" elas variam entre si, isto é, pela correlação entre elas. Nele fica claro que densidade de portas, densidade de janelas, continuidade da fachada e interfaces abertas estão mais próximas entre si do que as características associadas ao tipo isolado / torre, o que sugere a adequação da classificação proposta pelos autores.

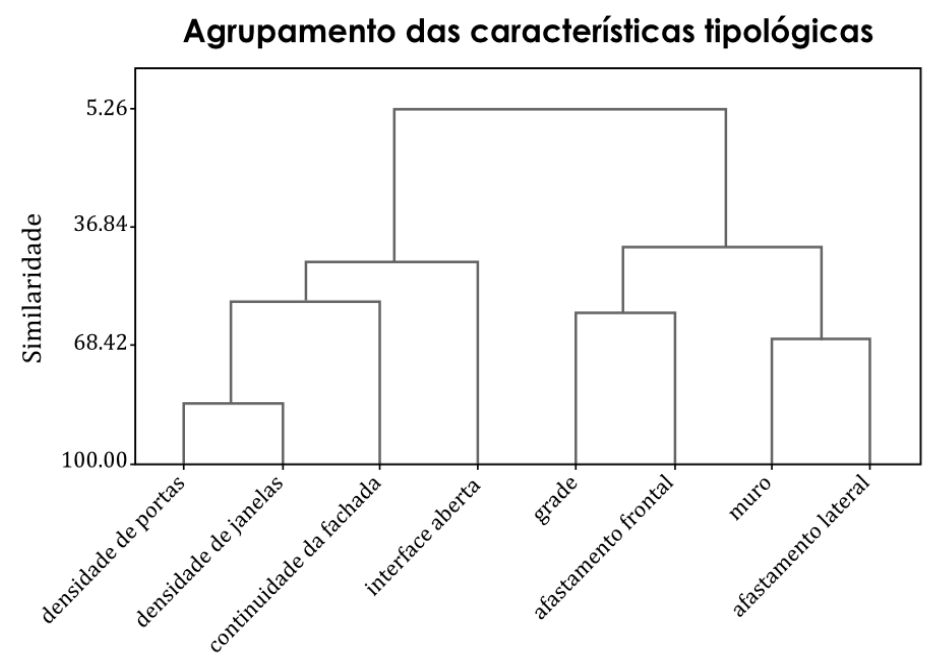

Figura 6 - Dendrograma mostrando a associação entre características tipológicas para 4.038 edificações em Porto Alegre, Rio Grande do Sul. Linhas mais próximas indicam maior correlação entre as variáveis.

Os agrupamentos mostram, à esquerda, as características que compõem o tipo compacto / contínuo e, à direita, aquelas que compõem o tipo isolado/torre. Fonte: traduzida de Netto et al. (2019).

Os resultados indicaram que, com efeito, os tipos contínuos se mostraram mais associados a alto movimento de pedestre (correlação $r=0,58)$, e os tipos isolados, a menor movimento de pedestres $(r=-0,66)$, mas apenas para os trechos com baixa acessibilidade (caracterizada por faixas com valores similares de escolha sintática global) (Tabela 1). Para a faixa de alta acessibilidade, aparentemente o tipo arquitetônico não é tão determinante, 
pelo menos para os resultados encontrados em Florianópolis. Outros resultados dignos de nota foram as correlações positivas da continuidade da fachada e da proporção de interfaces abertas dos lotes (ausência de muros ou grades) com o movimento de pedestres (MP). A densidade de janelas também mostrou correlação alta com o MP ( $r=0,62$ para baixa acessibilidade; e $r=0,57$ para alta), mas um exame posterior com regressão múltipla mostrou que isso se deve, provavelmente, à atuação da densidade populacional, que influencia a densidade de janelas e o movimento de pedestres.

Tabela 1 - Correlações entre características morfológicas das edificações e movimento de pedestres. Valores em negrito possuem significância estatística em 95\%

\begin{tabular}{|c|c|c|c|c|c|}
\hline \multirow{4}{*}{$\begin{array}{l}\text { Tipos arquitetônicos } \\
\text { (classes nominais) }\end{array}$} & \multirow[b]{3}{*}{ \% Tipo 1 (isolado) } & \multicolumn{2}{|c|}{ Baixa acessibilidade } & \multicolumn{2}{|c|}{ Alta acessibilidade } \\
\hline & & $r$ & p-valor & $r$ & p-valor \\
\hline & & $-0,66$ & 0,000 & $-0,21$ & 0,123 \\
\hline & \% Tipo 2 (híbrido) & 0,45 & 0,000 & 0,40 & 0,003 \\
\hline & \% Tipo 3 (compacto) & 0,58 & 0,000 & 0,07 & 0,591 \\
\hline Densidade & Densid. populacional & 0,69 & 0,000 & 0,71 & 0,000 \\
\hline \multirow[t]{2}{*}{ Afastamentos } & Afast. frontal & $-0,31$ & 0,005 & $-0,20$ & 0,149 \\
\hline & Afast. laterais & $-0,05$ & 0,666 & 0,28 & 0,044 \\
\hline \multirow[t]{2}{*}{ Fachada } & Tamanho fachada & 0,16 & 0,167 & 0,31 & 0,019 \\
\hline & Contin. fachada & 0,41 & 0,000 & 0,25 & 0,046 \\
\hline \multirow{2}{*}{ Permeabilidade } & Dens. portas & 0,20 & 0,078 & 0,27 & 0,046 \\
\hline & Dens. janelas (total) & 0,62 & 0,000 & 0,59 & 0,000 \\
\hline \multirow{3}{*}{ Fechamento lote } & \% Muro & $-0,21$ & 0,073 & $-0,29$ & 0,032 \\
\hline & $\%$ Grade & $-0,18$ & 0,109 & $-0,30$ & 0,028 \\
\hline & $\%$ Aberto & 0,30 & 0,008 & 0,46 & 0,000 \\
\hline & No térreo - frontal & $-0,29$ & 0,010 & $-0,23$ & 0,094 \\
\hline \multirow[t]{3}{*}{ Uso do solo } & \% Residencial & $-0,57$ & 0,000 & $-0,23$ & 0,097 \\
\hline & \% Comercial & 0,17 & 0,130 & 0,15 & 0,285 \\
\hline & Divers. usos & 0,32 & 0,001 & 0,39 & 0,003 \\
\hline
\end{tabular}

A coluna " $r$ " indica a correlação de Pearson entre a variável indicada e o movimento de pedestres (quantidade de pedestres por hora). O p-valor indica, em termos simples, a probabilidade de encontrar um valor de " $r$ " como o que foi encontrado, caso a correlação fosse, na realidade, inexistente (igual a 0,00). Valores menores que 0,05 significam que a diferença é estatisticamente significativa a 95\% e que, portanto, é pouco provável que o valor de correlação obtido se deva ao acaso. Fonte: adaptada de Saboya (2012)

\section{Tipo arquitetônico, uso do solo e ocorrência de crimes}

Em uma série de trabalhos cuja publicação se iniciou em 2012, Saboya estudou a relação entre os aspectos da forma construída e a ocorrência de crimes (Vivan \& Saboya, 2017; Saboya et al., 2016a; Barause \& Saboya, 2018), com ênfase em diferentes aspectos: visibilidade, usos do solo e configuração dos usos comerciais na edificação.

Vivan \& Saboya (2017) estudaram a relação de aspectos de visibilidade entre a edificação e o passeio com a ocorrência de crimes. Noventa e quatro trechos de logradouros em que aconteceram crimes e suas respectivas edificações foram levantados em Florianópolis e comparados a 47 trechos escolhidos aleatoriamente nas imediações, chamados de grupo de controle. 0 resultado preliminar foi contraintuitivo, mostrando associação entre maior visibilidade por janelas e interfaces de alta visibilidade à ocorrência de crimes. Um exame mais aprofundado mostrou que uma variável importante, o uso do solo, não havia sido controlada e, possivelmente, estava exercendo interferência na distribuição dos dados e nas conclusões derivadas deles. Segundo a hipótese levantada pelos autores, caso os usos comerciais estivessem associados tanto a uma maior visibilidade entre edificação e passeio quanto a uma maior ocorrência de crimes, é possível que a relação entre essas duas últimas fosse, na verdade, inexistente ou até mesmo inversa.

Com efeito, uma segunda análise considerando apenas os trechos de logradouros com $70 \%$ ou mais de usos residenciais, portanto controlando o uso do solo, mostrou que as conclusões se inverteram. Os trechos em que ocorreram crimes mostraram menor densidade de janelas e de portas e menor 
quantidade de interfaces de alta visibilidade, que não possuem muros nem vegetação densa o suficiente para impedir a visão entre o interior do lote e o passeio.

Esses resultados e o possível papel criminogênico dos usos comerciais deram origem a uma nova série de estudos que investigou aspectos morfológicos e de uso do solo e sua relação com a ocorrência de crimes. Saboya et al. (2016a) levantaram 122 pares de trechos urbanos em Florianópolis, compostos, cada um, de um trecho em que algum crime ocorreu e um trecho selecionado aleatoriamente nas imediações e com densidade populacional semelhante. Os resultados corroboraram em parte os resultados anteriores: a presença de interfaces de baixa visibilidade foi maior no grupo de crimes que no grupo controle, enquanto a densidade de janelas foi menor, ainda que nesse último caso não tenha atingido significância estatística a $95 \%$. Os usos comerciais mostraram-se realmente associados à ocorrência de crimes, assim como a diversidade de usos do solo (medida pelo índice de Gini-Simpson, que mede essencialmente o quão igualmente distribuídos estão os usos no trecho), a presença de lotes vazios e de edificações abandonadas. Por outro lado, o horário de funcionamento dos estabelecimentos não residenciais não mostrou associação com a ocorrência de crimes.

Barause \& Saboya (2018) aprofundaram o estudo sobre a relação dos tipos com o uso do solo e se perguntaram se usos comerciais de abrangência local e usos comerciais integrados a residências na mesma edificação teriam os mesmos efeitos criminogênicos que aqueles encontrados nos estudos anteriores. Para isso, levantaram as características tipológicas e de uso do solo das edificações de 96 trechos de logradouros na região de maior densidade populacional e construída de Florianópolis e as compararam à quantidade de crimes ocorridos nesses trechos entre 2014 e 2015. Os resultados não mostraram relação entre a proporção de usos comerciais de diferentes raios de abrangência (local, bairro ou cidade) com a ocorrência de crimes. Por outro lado, confirmaram a associação desta com os usos comerciais em geral e com a diversidade de usos, mas não com a proporção de usos comerciais integrados na mesma edificação que usos residenciais. Os autores atribuem esse resultado à possibilidade de vigilância proporcionada pelos usos residenciais em momentos em que os comércios se encontram fechados, diminuindo a incidência de áreas "cegas" ao longo do quarteirão proporcionada por usos comerciais isolados nos lotes.

\section{Considerações finais}

Os estudos sobre a forma urbana em Santa Catarina são numerosos e variados em suas abordagens, temas e conteúdos, o que dificulta a obtenção de conclusões que captem aspectos em comum entre eles ao mesmo tempo que contemplem suas peculiaridades. Entretanto, algumas considerações gerais sobre o conjunto dos trabalhos incluídos nesta revisão podem ser feitas. Chama a atenção, por exemplo, a quase completa ausência de autores internacionais importantes para a morfologia urbana, tais como Michael Conzen, Saverio Muratori, Gianfranco Caniggia, Jeremy Whitehand, Giancarlo Cataldi e Gian Luigi Maffei. De modo geral, os autores, as linhas teóricas e os trabalhos mais citados são Lynch (1960), Jacobs (1961), Hillier \& Hanson (1984), Santos \& Vogel (1985), Peponis (1989), Rossi (2001), Solà-Morales (1997), Villaça (2001), Holanda (2002) e Kohlsdorf (1996). Fica clara a influência da Universidade de Brasília (UnB) e, especialmente, de Frederico de Holanda nos trabalhos desenvolvidos em Santa Catarina, tanto diretamente, por meio de orientação de mestrado de Almir Reis e Ayrton Bueno, quanto indiretamente, como nos trabalhos de Renato Saboya, que foi aluno destes na graduação.

A grande maioria dos trabalhos é muito mais descritiva e discursiva do que quantitativa. Mesmo aqueles que usam quadros conceituais e metodológicos mais afeitos à quantificação, como a sintaxe espacial nos trabalhos de Reis \& Holanda (2017) e Bueno \& Holanda (2017), concentram seus esforços interpretativos nas relações e qualidades espaciais e formais, sem explorar a fundo as intensidades dos fenômenos capturadas pelas quantificações. Isso se reflete também na estrutura dos trabalhos e na descrição dos métodos, que não enfatizam, por exemplo, o tamanho da amostra nem se valem de técnicas estatísticas, como comparação entre médias, correlação ou regressão. Possivelmente por isso não ficam 
expressas nesses trabalhos ambições de generalizar seus resultados para outros contextos. Percebe-se neles também, ainda que em menor grau, uma certa ênfase prescritiva, às vezes mais explícita, às vezes mais velada, que sugere certos padrões espaciais e sociais como mais desejáveis e adequados que outros. O trabalho de Sugai (2015), o mais diferente do conjunto apresentado neste artigo tanto no que diz respeito à abordagem quanto às referências adotadas, também segue por linhas semelhantes: ainda que fundamentado em um vasto levantamento de dados, usa primordialmente técnicas discursivas para analisá-los e apoiar suas construções teóricas e conclusões.

Os trabalhos de Saboya (Saboya et al., 2015, 2016a; Carvalho \& Saboya, 2017; Vivan \& Saboya, 2017; Barause \& Saboya, 2018), por outro lado, têm enveredado por abordagens quantitativas, com tentativas de incluir amostras representativas de populações mais amplas e maior atenção à descrição do experimento, da operacionalização das variáveis e uso de técnicas estatísticas simples, como comparação entre médias e correlações. Entretanto, técnicas mais poderosas e avançadas, como regressões (lineares, múltiplas e logísticas) e análises de agrupamento ainda são timidamente adotadas. Outra diferença para os demais trabalhos é uma ênfase maior na forma urbana como variável independente, concentrando-se nos seus efeitos em outros aspectos do sistema urbano (outros elementos da forma, como a verticalização, ou aspectos socioespaciais, como o movimento de pedestres e a ocorrência de crimes), e dando relativamente pouca atenção aos processos socioeconômicos que originaram as formas estudadas. Os outros trabalhos tendem a considerar esse último aspecto de modo mais cuidadoso, enquanto tratam os efeitos de maneira menos sistemática e rigorosa.

Esse quadro geral, ainda que limitado pelas imposições de tempo e espaço, aponta algumas possibilidades para a continuidade dos estudos sobre a forma urbana em Santa Catarina. Em primeiro lugar, um diálogo com outros autores poderia se mostrar benéfico e enriquecer a reflexão sobre a forma urbana, especialmente aqueles citados no início desta seção, que possuem uma longa tradição no campo da morfologia urbana e geraram uma grande quantidade de trabalhos aplicando, estendendo e revisando seus pressupostos. Segundo, a adoção de estudos de natureza qualitativa e quantitativa parece ser salutar para o campo, pois as virtudes de uma podem complementar e ajudar a superar as fragilidades da outra. Entretanto, ainda parece haver margem para uma maior integração entre elas, o que poderia fazer com que essa complementaridade fosse alcançada de maneira mais eficiente. Isso pode ser feito no mesmo trabalho ou em estudos conjuntos, de um mesmo autor ou, preferencialmente, de diferentes pesquisadores que juntem forças para analisar fenômenos de interesse comum. Redes de colaboração mais abrangentes poderiam também trazer um diálogo com outras realidades do Brasil e do mundo.

\section{Referências}

Abramo, P. (2001). Mercado e ordem urbana: do caos à teoria da localização residencial. Rio de Janeiro: Bertrand Brasil.

Ângelo, C., Ludwig, C., Trezub, D., Bueno, A., \& Reis, A. F. (2017). Forma e imagem: duas abordagens distintas. In A. Bueno, A. F. Reis, \& R. T. Saboya (Eds.), Sintaxe Catarina (Coleção Urbanismo e Arquitetura da Cidade, pp. 17-32). Florianópolis: Editora UFSC.

Barause, L., \& Saboya, R. T. (2018). Forma arquitetônica e usos do solo: um estudo sobre seus efeitos na ocorrência de crimes. Ambiente Construído, 18(4), 427-444. http://dx.doi.org/10.1590/s1678-86212018000400314.

Bueno, A., \& Holanda, F. (2017). Apropriação social em balneários costeiros da Ilha de Santa Catarina. In A. Bueno, A. F. Reis, \& R. T. Saboya (Eds.), Sintaxe Catarina (Coleção Urbanismo e Arquitetura da Cidade, pp. 33-76). Florianópolis: Editora UFSC.

Carvalho, A., \& Saboya, R. T. (2017). A localização residencial em uma cidade vertical: um estudo sintático em Florianópolis. urbe. Revista Brasileira de Gestão Urbana, 9(3), 414-429. http://dx.doi.org/10.1590/21753369.009.003.ao03. 
Conzen, M. R. G. (2004). Morphogenesis, morphological regions, and secular human agency in the historic townscape, as exemplified by Ludlow. In M. P. Conzen (Ed.), Thinking about urban form: papers on urban morphology, 1932-1998 (pp. 116-142). Oxford: Peter Lang.

Cullen, G. (1983). Paisagem urbana. São Paulo: Martins Fontes.

Flickr. (2019). Recuperado em 22 de setembro de 2019, de https://www.flickr.com/photos/157271073@N08/albums

Hillier, B., \& Hanson, J. (1984). The social logic of space. Cambridge: Cambridge University Press. http://dx.doi.org/10.1017/CB09780511597237.

Holanda, F. R. B. (2002). O espaço de exceção. Brasília: Editora UnB.

Instituto Brasileiro de Geografia e Estatística - IBGE. (2010). Censo demográfico 2010. Rio de Janeiro: IBGE. Jacobs, J. (1961). The death and life of great American cities. New York: Vintage Books.

Kohlsdorf, M. E. (1996). A apreensão da forma da cidade. Brasília: Editora da UnB.

Krafta, R. (1994). Modelling intraurban configurational development. Environment and Planning. B, Planning \& Design, 21(1), 67-82. http://dx.doi.org/10.1068/b210067.

Kronenberger, B. C., \& Saboya, R. T. (2019). Entre a servidão e a beira-mar: um estudo configuracional da segregação socioespacial na Área Conurbada de Florianópolis (ACF), Brasil. urbe. Revista Brasileira de Gestão Urbana, 11, e20170227. http://dx.doi.org/10.1590/2175-3369.011.e20170227.

Lefebvre, H. (2008). O direito à cidade. São Paulo: Centauro.

Lojkine, J. (1997). O estado capitalista e a questão urbana. São Paulo: Martins Fontes.

Lynch, K. (1960). The image of the city. Cambridge: The M.I.T. Press.

Netto, V. M., Vargas, J. C., \& Saboya, R. (2012). (Buscando) os efeitos sociais da morfologia arquitetônica. urbe. Revista Brasileira de Gestão Urbana, 4(2). http://dx.doi.org/10.7213/urbe.7400.

Netto, V. M., Vargas, J. C., \& Saboya, R. (2019). The social effects of architecture: built form and social sustainability. In R. Keivani, \& M. R. Shirazi (Eds.), Urban social sustainability: theory, practice and policy (pp. 125-148). London: Routledge. http://dx.doi.org/10.4324/9781315115740-7.

Peponis, J. (1989). Space, culture and urban design in late modernism and after. Ekistics, 56(334-335), 93-108.

Reis, A. F. (2012). Ilha de Santa Catarina: permanências e transformações. Florianópolis: Editora UFSC.

Reis, A. F., \& Holanda, F. (2017). Forma e apropriação do espaço público: um estudo sintático do Centro de Florianópolis. In A. Bueno, A. F. Reis, \& R. T. Saboya (Eds.), Sintaxe Catarina (Coleção Urbanismo e Arquitetura da Cidade, pp. 17-32). Florianópolis: Editora UFSC.

Rossi, A. (2001). A arquitetura da cidade. Martins Fontes.

Saaty, T. L. (1990). How to make a decision: the analytic hierarchy process. European Journal of Operational Research, 48(1), 9-26. http://dx.doi.org/10.1016/0377-2217(90)90057-I.

Saboya, R. T. (2012). Desempenho urbano e morfologia arquitetônica: relações entre predominância tipológica e a vitalidade social e microeconômica em cidades brasileiras (Módulo Arq/UFSC) (pp. 72). Florianópolis: UFSC.

Relatório de Pesquisa.

Saboya, R., Netto, V. M., \& Vargas, J. C. (2015). Fatores morfológicos da vitalidade urbana: uma investigação sobre o tipo arquitetônico e seus efeitos. Arquitextos, 180.02. Recuperado em 22 de setembro de 2019, de http://vitruvius.com.br/revistas/read/arquitextos/15.180/5554

Saboya, R., Banki, G. H., \& Santana, J. M. A. (2016a). Uso do solo, visibilidade e ocorrência de crimes: um estudo de caso em Florianópolis, Santa Catarina. Oculum Ensaios, 13(2), 255. http://dx.doi.org/10.24220/2318$0919 v 13 n 2 a 2990$. 
Saboya, R., Reis, A., \& Bueno, A. (2016b). Continuidades e descontinuidades urbanas à beira-mar: uma leitura morfológica e configuracional da área conurbada de Florianópolis. Oculum Ensaios, 13(1), 129-152.

http://dx.doi.org/10.24220/2318-0919v13n1a2756.

Sadowski, D., \& Rossetto, A. M. (2018). Ingleses e o Rio Capivari: forma urbana, espaços públicos, natureza e urbanidade. Risco Revista de Pesquisa em Arquitetura e Urbanismo, 16(2), 100-112.

http://dx.doi.org/10.11606/issn.1984-4506.v16i2p100-112.

Santos, C. N., \& Vogel, A. (1985). Quando a rua vira casa. São Paulo: Projeto.

Skalee, M., \& Reis, A. F. (2008). Crescimento urbano-turístico: traçado e permanências urbanas em Balneário Camboriú. Scripta Nova: Revista Electrónica de Geografía y Ciencias Sociales, 12(270).

http://dx.doi.org/10.1344/sn2008.12.1512.

Solà-Morales, M. (1997). Las formas de crecimiento urbano. España: Universitat Politècnica de Catalunya.

Sugai, M. I. (2015). Segregação silenciosa: investimentos públicos e dinâmica socioespacial na área conurbada de Florianópolis (1970-2000). Florianópolis: Editora UFSC.

Tomelin, C. A., Rossini, D. M., Fontanella, F. L. P., dos Anjos, F. A., Oliveira, J. P., \& Tricarico, L. T. (2012). Turismo cultural e paisagem urbana: análise dos cascos históricos de Itajaí e de São Francisco do Sul - Santa Catarina, Brasil. Revista Turismo \& Desenvolvimento, 3(17-18), 1495-1508.

Turner, A. (2007). From axial to road-centre lines: a new representation for space syntax and a new model of route choice for transport network analysis. Environment and Planning. B, Planning \& Design, 34(3), 539-555. http://dx.doi.org/10.1068/b32067.

Veiga, E. V. (2010). Florianópolis: memória urbana (2a ed. rev. e ampliada). Florianópolis: Fundação Cultural de Florianópolis Franklin Cascaes.

Villaça, F. (2001). Espaço intra-urbano no Brasil. São Paulo: Studio Nobel: FAPESP: Lincoln Institute.

Villaça, F. (2012). Reflexões sobre as cidades brasileiras. São Paulo: Studio Nobel.

Vivan, M., \& Saboya, R. (2017). Arquitetura, espaço urbano e criminalidade: efeitos da visibilidade na distribuição da ocorrência de crimes. In V. Netto, R. Saboya, J. C. Vargas, \& T. Carvalho (Eds.), Efeitos da Arquitetura: os impactos da urbanização contemporânea no Brasil (pp. 163-182). Brasília: FRBH.

Editores convidados: Vitor Oliveira (Universidade do Porto, Portugal) e Bruno Zaitter (PUCPR, Brasil)

Recebido: Set. 22, 2019

Aprovado: Dez. 05, 2019 


\section{Errata}

No artigo "O estudo da forma urbana em Santa Catarina, Brasil", com o número de DOI https://doi.org/10.1590/2175-3369.012.e20190269, publicado na urbe. Revista Brasileira de Gestão Urbana, vol. 12, e20190269,

onde se lia:

Sessão Especial

leia-se:

Seção Temática: 0 Estudo da Forma Urbana no Brasil (Editores convidados: Vitor Oliveira e Bruno Zaitter)

onde se lia:

Editor: Bruno Zaitter

leia-se:

Editores convidados: Vitor Oliveira (Universidade do Porto, Portugal) e Bruno Zaitter (PUCPR, Brasil) 


\section{Errata}

No artigo "O estudo da forma urbana em Santa Catarina, Brasil", com o número de DOI https://doi.org/10.1590/2175-3369.012.e20190269, publicado na urbe. Revista Brasileira de Gestão Urbana, vol. 13, e20190269, na página 2,

onde se lia:

"Este artigo busca fazer uma revisão de alguns principais dos trabalhos e das linhas de pesquisa relacionados a esses temas [...]"

leia-se:

"Este artigo busca fazer uma revisão de algumas das principais linhas de pesquisa e trabalhos relacionados a esses temas $[\ldots . . . "$ 